\title{
Negotiations over mineral extraction titles with bilateral asymmetric information: the case of developing countries
}

\author{
R. D Mounanga Mabiala \& C. Yang \\ Southwestern University of Finance and Economics, China
}

\begin{abstract}
Why do negotiations between governments of developing countries and multinational mining companies often yield inefficient trade over acquisitions of mineral extraction titles? Adverse selection is one of the main reasons. When the terms of contracts are prepared on the basis of erroneous information, the resulting contract will be inefficient. This paper presents a theoretical model of negotiations over mineral extraction titles with bilateral asymmetric information; where a mining extraction title is negotiated between a developing country's government and a multinational mining company. When both the mine owner and the mine operator have private information at the time of trading, and when each contracting party has a continuous distribution of types, with strictly positive density function, trade inefficiency is the inevitable result. However, it is still possible to reduce the inefficiency if the agents' valuations are traded at auction, or if they resort to arbitration. Therefore, as a second-best optimal contract, two strategies remain possible; the simple double auction or the final offer arbitration. In both strategies, the average price bid amount is the optimal result of the negotiation.
\end{abstract}

Keywords: mineral extraction titles, adverse selection, contract inefficiency, second-best outcome, final offer-arbitration, double auction.

\section{Introduction}

A bilateral contract is an agreement in which each of the parties to the contract makes a promise to the other party. Adverse selection may arise, when both parties have private information, and then each are imperfectly informed about the characteristics of the other party.

In this paper, the complete analysis of negotiation will take into account the following requirements. Firstly, we assume that the mining firm has access to more information than the mine owner about the resource stock level, the nature of the ores extracted, the diversity of mineral composition, and the quality of the resource. Secondly, we assume that the mine owner's specific context is about his commitment. He may or may not commit himself to the concession contract proposed to the mine operator. Thirdly, we suppose that the agents' valuation for the non-renewable resource is equal to their expected mining revenue. Therefore 
the asymmetric variable is their valuation for the mineral deposit. Finally, we assume that the arbitrator's preferred settlement is normally distributed around its mean and its standard deviation.

\section{The formal framework}

As Dewatripont and Bolton [1] analysed, in presence of bilateral asymmetric information, it may not always be possible to achieve trade. One assumes that the two risk neutral agents have private, independently distributed information about their valuation. However, the agent expected valuation has differentiable strict positive density. We can prove that efficient trade cannot be achieved if contracting takes place at the interim stage. We should firstly determine the set of implementable trades that satisfy interim individual rationality, and then show that efficient trading is not in this set.

\subsection{The set of implementable trades}

Applying the revelation principle ; the mining owner and the mining operator's problem is to choose a revelation contract. The contingent on announcement satisfies incentive-compatibility and individual rationality constraints, and maximizes the expected gain from trade; thus in any truth-telling equilibrium we have:

-from the mining owner:

$$
\begin{aligned}
& \operatorname{Pr}\left(E\left(\pi_{g}\right)\right)=\int_{E\left(\pi_{f}\right)}^{-\overline{E\left(\pi_{f}\right)}} \operatorname{Pr}\left(E\left(\pi_{g}\right) ; E\left(\pi_{f}\right)\right) f_{f}\left(\pi_{f}\right) d\left(\pi_{f}\right) \text { seller expected probability of trade } \\
& \eta_{g}\left(E\left(\pi_{g}\right)\right)=\int_{E\left(\underline{\pi}_{f}\right)}^{-} H\left(E\left(\pi_{g}\right), E\left(\pi_{f}\right)\right) f_{f}\left(\pi_{f}\right) d\left(\pi_{f}\right) \text { the expected price from the firm }
\end{aligned}
$$

-from the mining operator:

$$
\begin{aligned}
& \operatorname{Pr}\left(E\left(\pi_{f}\right)\right)=\int_{E\left(\pi_{g}\right)}^{\left.-\overline{\pi_{g}}\right)} \operatorname{Pr}\left(E\left(\pi_{g}\right) ; E\left(\pi_{f}\right)\right) f_{g}\left(\pi_{f}\right) d\left(\pi_{f}\right)_{\text {buyer expected probability of trade }} \\
& \eta_{f}\left(E\left(\pi_{f}\right)\right)=\int_{E\left(\underline{\pi}_{g}\right)}^{-} H\left(E\left(\pi_{g}\right) ; E\left(\pi_{f}\right)\right) f_{g}\left(E\left(\pi_{g}\right)\right) d E\left(\pi_{g}\right) \text { the expected price from the state }
\end{aligned}
$$


Thus, each agent expected payoff under the contract can be written as:

$$
U_{g}(E(\pi))=\eta_{g}(\pi)-E(\pi) \operatorname{P}(E(\pi))
$$

and

$$
U_{f}\left(E\left(\pi_{f}\right)\right)=E\left(\pi_{f}\right) \operatorname{Pr}\left(E\left(\pi_{f}\right)\right)-\eta_{f}\left(E\left(\pi_{f}\right)\right)
$$

The incentive-compatibility and interim individual-rationality constraints for both agents are then given by:

$$
\begin{aligned}
& U_{g}\left(E\left(\pi_{g}\right)\right) \geq \eta_{g}\left(E\left(\pi_{g}\right)\right)-E\left(\pi_{g}\right) \operatorname{Pr}\left(E\left(\pi_{g}\right)\right) \forall \pi_{g} \in\left[E\left(\pi_{-s}\right) ; E\left(\pi_{s}\right)\right] \text { State incentive constraint } \\
& U_{f}\left(E\left(\pi_{f}\right)\right) \geq E\left(\pi_{f}\right) \operatorname{Pr}\left(E\left(\pi_{f}\right)\right)-\eta_{f}\left(E\left(\pi_{f}\right)\right) \forall \pi_{f} \in\left[E\left(\underline{\pi}_{f}\right) ; E\left(\pi_{f}\right)\right] \text { firm incentive constraint } \\
& U_{g}\left(E\left(\pi_{g}\right)\right) \geq 0 \forall \pi_{g} \in\left[E\left(\underline{\pi}_{g}\right) ; E\left(\bar{\pi}_{g}\right)\right] \text { State individual rationality } \\
& U_{f}\left(E\left(\pi_{f}\right)\right) \geq 0 \forall \pi_{f} \in\left[E\left(\underline{\pi}_{f}\right) ; E\left(\pi_{f}\right)\right] \text { firm individual rationality }
\end{aligned}
$$

Assuming that agents' preferences satisfy the single-crossing condition problem, only the individual-rationality constraints for the lowest types may be binding:

$$
U_{g}\left(E\left(\pi_{s}\right)\right) \geq 0
$$

and

$$
U_{f}\left(E\left(\underline{\pi}_{f}\right)\right) \geq 0
$$

The lowest expected valuation of the government is $E\left(\bar{\pi}_{g}\right)$ (his opportunity cost).

Each agent expected probability of trade must be monotonically increasing in his type; then by using the envelope theorem (by integrating), we obtain:

$$
U_{g}\left(E\left(\pi_{g}\right)\right)=U_{g}\left(E\left(\bar{\pi}_{g}\right)\right)+\int_{E\left(\pi_{g}\right)}^{E\left(\bar{\pi}_{g}\right)} \operatorname{Pr}\left(E\left(X_{g}\right)\right) d E\left(X_{g}\right)
$$

symmetrically,

$$
U_{f}\left(E\left(\pi_{f}\right)\right)=U_{f}\left(E\left(\underline{\pi}_{f}\right)\right)+\int_{E\left(\underline{\pi}_{f}\right)}^{E\left(\pi_{f}\right)} \operatorname{Pr}\left(E\left(X_{f}\right)\right) d E\left(X_{f}\right)
$$

It simply means that, given monotonicity, only local incentive compatibility constraints matter, so the mining operator and the mining owner's informational values are simply the sum of the lowest buyer's expected bid and the integral of 
all inframarginal buyers' expected marginal value. More exactly, the mining owner's gain by pretending that he is reluctant to sell the extraction rights of the mining resource, so as to induce the mining operator to offer a higher expected price. Therefore, he would always claim to have the highest possible expected opportunity cost. To induce the government to truthfully announce a valuation; the mining operator must therefore be given some informational value, and giving him this value raises the likelihood of trade, when he announces a lower expected opportunity cost. At the same time, the mining company will always underestimate his valuation of the non-renewable resource. Thus, any firm must be given some price to be induced to tell the truth, or equivalently the likelihood of trade must be increasing in the company's announced valuation.

\subsection{Agent negative virtual surplus}

Efficient trade for this contract requires that trade take place with

$$
\operatorname{Pr}\left(E\left(\pi_{g}\right) ; E\left(\pi_{f}\right)\right)=1 \forall E\left(\pi_{g}\right) \leq E\left(\pi_{f}\right)
$$

and

$$
\operatorname{Pr}\left(E\left(\pi_{g}\right) ; E\left(\pi_{f}\right)\right)=0 \forall E\left(\pi_{f}\right) \leq E\left(\pi_{g}\right)
$$

Knowing that, the mining contract imposes the first-best trade probabilities and satisfies all incentive-compatible constraints; we show that mining contract violates the interim individual rationality constraints [1]. To prove this result, observe that (putting E1 into E5, and E5 into E13, we obtain E17):

$$
\eta_{g}\left(E\left(\pi_{g}\right)\right)=E\left(\pi_{g}\right) \int_{E\left(\underline{\pi}_{g}\right)}^{E\left(\bar{\pi}_{g}\right)} \operatorname{Pr}\left(E\left(\pi_{g}\right) ; E\left(\pi_{g}\right)\right) f_{g}\left(E\left(\pi_{g}\right)\right) d E\left(\pi_{g}\right)+U_{g}\left(E\left(\bar{\pi}_{f}\right)\right)+\int_{E\left(\pi_{g}\right)}^{E\left(\bar{\pi}_{g}\right)} \operatorname{Pr}\left(E\left(X_{g}\right)\right) d E\left(X_{f}\right)
$$

Symmetrically (putting E3 into E6, and E6 into E14, we obtain E18),

$$
\eta_{f}\left(E\left(\pi_{f}\right)\right)=E\left(\pi_{f}\right) \int_{E\left(\underline{\pi}_{f}\right)}^{E\left(\bar{\pi}_{f}\right)} \operatorname{Pr}\left(E\left(\pi_{f}\right) ; E\left(\pi_{f}\right)\right) f_{f}\left(E\left(\pi_{f}\right)\right) d E\left(\pi_{f}\right)-U_{f}\left(E\left(\underline{\pi}_{f}\right)\right)-\int_{E\left(\underline{\pi}_{f}\right)}^{E\left(\pi_{f}\right)} \operatorname{Pr}\left(E\left(x_{f}\right)\right) d E\left(x_{f}\right)
$$

Knowing that the sum of the expected payment cannot exceed the total transfer available, then [2]:

$$
\begin{gathered}
\int_{E\left(\underline{\pi}_{g}\right)}^{E\left(\pi_{g}\right)} \eta_{g}\left(E\left(\pi_{g}\right)\right) f_{g}\left(E\left(\pi_{g}\right) ; E\left(\pi_{f}\right)\right) d E\left(\pi_{g}\right)+\int_{E\left(\underline{\pi}_{f}\right)}^{-\bar{E}\left(\pi_{f}\right)} \eta_{f}\left(E\left(\pi_{f}\right)\right) f_{f}\left(E\left(\pi_{g}\right) ; E\left(\pi_{f}\right)\right) d E\left(\pi_{f}\right) \leq \\
\int_{E\left(\underline{\pi}_{f}\right)}^{E\left(\bar{\pi}_{f}\right)} \int_{E\left(\underline{\pi}_{g}\right)}^{E\left(\bar{\pi}_{g}\right)} H\left(E\left(\pi_{g}\right) ; E\left(\pi_{f}\right)\right) f_{g}\left(E\left(\pi_{g}\right)\right) f_{f}\left(E\left(\pi_{f}\right)\right) d E\left(\pi_{g}\right) d E\left(\pi_{f}\right)
\end{gathered}
$$

with $H\left(E\left(\pi_{g}\right) ; E\left(\pi_{f}\right)\right)=\frac{\eta_{g}+\eta_{f}}{2}$ from the total transfer available, we can express that the mining operator expected surplus (from E18 we obtain E20): 


$$
\begin{aligned}
& \int_{E\left(\underline{\pi}_{f}\right)}^{E\left(\bar{\pi}_{f}\right)} \int_{E\left(\underline{\pi}_{g}\right)}^{\left.\overline{\pi_{\pi_{g}}}\right)} H\left(E\left(\pi_{f}\right) ; E\left(\pi_{g}\right)\right) f_{g}\left(E\left(\pi_{g}\right)\right) f_{f}\left(E\left(\pi_{f}\right)\right) d_{E\left(\pi_{g}\right)} d_{E\left(\pi_{f}\right)}=\int_{E\left(\underline{\pi}_{f}\right)}^{E\left(\bar{\pi}_{f}\right)} \int_{E\left(\underline{\pi}_{g}\right)}^{E\left(\bar{\pi}_{g}\right)} E\left(\pi_{f}\right) \operatorname{Pr}\left(E\left(\pi_{f}\right) ; E\left(\pi_{g}\right)\right) f_{g}\left(E\left(\pi_{g}\right)\right) f_{f}\left(E\left(\pi_{f}\right)\right) \\
& d E\left(\pi_{g}\right) d E\left(\pi_{f}\right)-U_{f}\left(E\left(\pi_{f}\right)\right)-\int_{E\left(\pi_{g}\right)}^{E\left(\pi_{g}\right)}\left[\int_{E\left(\pi_{f}\right)}^{E\left(\pi_{f}\right)} \int_{E\left(\pi_{f}\right)}^{-} \operatorname{Pr}\left(E\left(\pi_{f}\right) ; E\left(\pi_{g}\right)\right) f_{g}\left(E\left(\pi_{g}\right)\right) f_{f}\left(E\left(\pi_{f}\right)\right)\right] d_{E\left(\pi_{g}\right)} d_{E\left(\pi_{f}\right)}
\end{aligned}
$$

Therefore, using Fubini's theorem - proposition 1 - we obtain:

$$
\begin{aligned}
& \int_{E\left(\pi_{f}\right)}^{E\left(\bar{\pi}_{f}\right)} \int_{E\left(\underline{\pi}_{g}\right)}^{E\left(\bar{\pi}_{g}\right)} H\left(E\left(\pi_{f}\right) ; E\left(\pi_{g}\right)\right) f_{g}\left(E\left(\pi_{g}\right)\right) f_{f}\left(E\left(\pi_{f}\right)\right) d E\left(\pi_{g}\right) d E\left(\pi_{f}\right)=\int_{E\left(\pi_{f}\right)}^{E\left(\bar{\pi}_{f}\right)} \int_{E\left(\underline{\pi}_{g}\right)}^{E\left(\bar{\pi}_{g}\right)} \operatorname{Pr}\left(E\left(\pi_{f}\right) ; E\left(\pi_{g}\right)\right)\left[E\left(\pi_{f}\right)-\frac{1-F_{f}\left(E\left(\pi_{f}\right)\right)}{f_{f}\left(E\left(\pi_{f}\right)\right)}\right] \\
& f_{g}\left(E\left(\pi_{g}\right)\right) f_{f}\left(E\left(\pi_{f}\right)\right) d E\left(\pi_{g}\right) d E\left(\pi_{f}\right)-U_{f}\left(E\left(\underline{\pi}_{f}\right)\right)
\end{aligned}
$$

The following expression

$$
\int_{E\left(\underline{\pi}_{f}\right)}^{E\left(\pi_{f}\right)} \int_{E\left(\pi_{g}\right)}^{E\left(\pi_{g}\right)} \operatorname{Pr}\left(E\left(\pi_{g}\right) ; E\left(\pi_{f}\right)\right)\left[E\left(\pi_{f}\right)-\frac{1-F_{f}\left(E\left(\pi_{f}\right)\right.}{f_{f}\left(E\left(\pi_{f}\right)\right)}\right] f_{g}\left(E\left(\pi_{g}\right)\right) f_{f}\left(E\left(\pi_{f}\right)\right) d E\left(\pi_{g}\right) d E\left(\pi_{f}\right)-U_{f}\left(E\left(\pi_{f}\right)\right)
$$

in the adverse selection literature [2], represents the mining operators virtual expected revenue, which includes the expected revenue plus the informational expected revenue, minus the reciprocal of the value of the density function of the mining operator's preferred settlement. More precisely, the hazard rate is the cost of screening the information relative to the multinational mining firm's expected mining revenue.

Symmetrically, from the total transfer available, we can express the government expected surplus. (from E17 we obtain E23):

$$
\begin{aligned}
& \int_{E\left(\underline{\pi}_{f}\right)}^{E\left(\pi_{f}\right)} \int_{E\left(\underline{\pi}_{g}\right)}^{E\left(\pi_{g}\right)} H\left(E\left(\pi_{f}\right) ; E\left(\pi_{g}\right)\right) f_{g}\left(E\left(\pi_{g}\right)\right) f_{f}\left(E\left(\pi_{f}\right)\right) d E\left(\pi_{g}\right) d E\left(\pi_{f}\right)=\int_{E\left(\underline{\pi}_{f}\right)}^{E\left(\pi_{f}\right)} \int_{E\left(\underline{\pi}_{g}\right)}^{E\left(\pi_{g}\right)} E\left(\pi_{g}\right) \operatorname{Pr}\left(E\left(\pi_{f}\right) ; E\left(\pi_{g}\right)\right) f_{g}\left(E\left(\pi_{g}\right)\right) f_{f}
\end{aligned}
$$

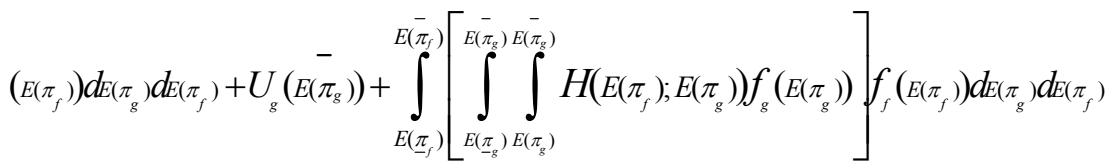

Therefore, using Fubini's theorem - proposition 1 - we obtain: 


$$
\begin{aligned}
& \int_{E\left(\pi_{f}\right)}^{-\bar{E}\left(\pi_{-}\right)} \int_{E\left(\pi_{g}\right)}^{-} H\left(E\left(\pi_{f}\right) ; E\left(\pi_{g}\right)\right) f_{g}\left(E\left(\pi_{g}\right)\right) f_{f}\left(E\left(\pi_{f}\right)\right) d E\left(\pi_{g}\right) d E\left(\pi_{f}\right)=\int_{E\left(\pi_{f}\right)}^{-} \int_{E\left(\pi_{-g}\right)}^{-} \operatorname{Pr}\left(E\left(\pi_{f}\right) ; E\left(\pi_{g}\right)\right)\left[E\left(\pi_{g}\right)+\frac{F\left(E\left(\pi_{g}\right)\right)}{f_{g}\left(E\left(\pi_{g}\right)\right)}\right] \\
& f_{g}\left(E\left(\pi_{g}\right)\right) f_{f}\left(E\left(\pi_{f}\right)\right) d E\left(\pi_{g}\right) d E\left(\pi_{f}\right)+U_{g}\left(E\left(\pi_{g}\right)\right)
\end{aligned}
$$

The following expression:

$$
\int_{E\left(\underline{\pi}_{f}\right)}^{-} \int_{E\left(\pi_{g}\right)}^{E\left(\pi_{f}\right)} \mathrm{P}\left(E\left(\pi_{g}\right) ; E\left(\pi_{f}\right)\right)\left[E\left(\pi_{g}\right)+\frac{F_{g}\left(E\left(\pi_{g}\right)\right)}{f_{g}\left(E\left(\pi_{g}\right)\right)}\right] f_{g}\left(E\left(\pi_{g}\right)\right) f_{f}\left(E\left(\pi_{f}\right)\right) d E\left(\pi_{g}\right) d E\left(\pi_{f}\right)+U_{g}\left(E\left(\pi_{g}\right)\right)
$$

represents the mining owner virtual expected price, which includes the expected price plus the informational expected price borne by the government. More precisely, the hazard rate is the cost of screening the information relative to the government's expected price. Rearranging the last two expressions, one then obtains the participation constraint $(\mathrm{E} 21+\mathrm{E} 24=\mathrm{E} 26)$ :

$$
\begin{aligned}
& U_{g}\left(E\left(\pi_{g}\right)\right)+U_{f}\left(E\left(\pi_{-f}\right)\right)=\int_{E\left(\pi_{-f}\right) E\left(\pi_{-g}\right)}^{-} \int_{\left(\pi_{f}\right)}^{-} \mathrm{E}\left(E\left(\pi_{g}\right)\right. \\
& \left.f_{g}\left(E\left(\pi_{g}\right)\right) f_{f}\left(E\left(\pi_{f}\right)\right) d E\left(\pi_{g}\right)\right) d E\left(\pi_{f}\right)
\end{aligned}
$$

The right hand side of this equation gives the virtual surplus of the mining company and the government. This expected payoff should be nonnegative to satisfy both interim individual rationality constraints. Now one can show that the virtual surplus is negative. Substituting the probability of trade in the equation above, with the first-best trading probability one obtains a negative virtual surplus (from E26, we obtain E27)

$$
U_{g}\left(E\left(\pi_{g}\right)\right)+U_{f}\left(E\left(\pi_{f}\right)\right)=-\left[\int_{E\left(\tilde{\pi}_{f}\right)}^{E\left(\pi_{f}\right)}\left[1-F_{f}\left(E\left(\pi_{f}\right)\right)\right] d E\left(\pi_{f}\right)+\int_{E\left(\pi_{f}\right)}^{-}\left(\left(E\left(\pi_{f}\right)-E\left(\pi_{f}\right)\right) f_{f}\left(E\left(\pi_{f}\right)\right)\right) d E\left(\pi_{f}\right)\right]
$$

When the firms expected valuation rises to the governments highest expected opportunity cost, then the surplus is clearly negative (E28).

$$
U_{g}\left(E\left(\bar{\pi}_{g}\right)\right)+U_{f}\left(E\left(\underline{\pi}_{f}\right)\right)=-\int_{E\left(\underline{\pi}_{f}\right)}^{E\left(\bar{\pi}_{g}\right)}\left[1-F_{f}\left(E\left(\pi_{f}\right)\right)\right] d E\left(\pi_{f}\right) \leq 0
$$

This result establishes that this bilateral trading problem, where both the government and the mining company have private information at the time of 
trading, always results in trade inefficiency when each contracting party has a continuous distribution of types, with the strictly positive density function [3].

\section{The second-best contract through the double auction}

The government could impose a level payment, or ask a price, which begins bargaining (which might be his highest expected amount): $H\left(E\left(\pi_{g}\right) ; E\left(\pi_{f}\right)\right)$.

More exactly, we assume that at this asking price, he might agree to sell to the mining operator the extraction rights of the non-renewable resource. On other side, the mining operator makes a bid. In this section, one will characterize the Bayesian equilibrium of this double auction contract; then show that the simple double auction is the second best optimal contract.

\subsection{Characterize the Bayesian equilibrium}

One assumes that the company simultaneously names an offer price. The mining owner strategy is the price he will ask for each possible valuation. Thus, a pair strategy is Bayesian Nash equilibrium if the following two conditions hold:

$$
\begin{gathered}
\forall E\left(\pi_{f}\right) \in[0 ; 1] \eta_{f}\left(E\left(\pi_{f}\right)\right) \text { solves } \\
\max _{f}\left[\begin{array}{c}
\left.E\left(\pi_{f}\right)-\frac{\eta_{f}\left(\pi_{f}\right)+E\left[\eta_{g}\left(E\left(\pi_{g}\right)\right) / E\left(\pi_{f}\right) \geq \eta_{g}\left(E\left(\pi_{g}\right)\right)\right.}{}\right] \\
\forall E\left(\pi_{g}\right) \in[0 ; 1] \eta_{g}\left(E\left(\pi_{g}\right)\right) \text { solves } \\
2
\end{array}\right] \operatorname{Pr}\left\{\eta_{f} \geq \eta_{g}\left(E\left(\pi_{g}\right)\right)\right\} \\
\max _{g}\left[\frac{\eta_{g}\left(\pi_{g}\right)+E\left[\eta_{f}\left(E\left(\pi_{f}\right)\right) / \eta_{g}\left(E\left(\pi_{s}\right)\right) \geq \eta_{f}\right]}{2}-E\left(\pi_{g}\right)\right] \operatorname{Pr}\left\{\eta_{g}\left(E\left(\pi_{g}\right)\right) \geq \eta_{f}\right\}
\end{gathered}
$$

Assuming that their strategies are linear, and firm-government strategies are best responses to each other these strategies are indeed Bayesian-Nash equilibrium.

The linear Bayesian Nash equilibrium gives the pair strategy:

$$
\left\{\begin{array}{l}
2 \\
-E\left(\pi_{g}\right)+\frac{1}{-} ;-^{2} E\left(\pi_{f}\right)+\frac{1}{12}
\end{array}\right\}
$$

is the Bayesian Nash equilibrium; and trade will occur at:

$$
\eta_{f}\left(E\left(\pi_{f}\right)\right) \geq \eta_{g}\left(E\left(\pi_{g}\right)\right)
$$




\subsection{The simple double auction as the second best optimal contract}

One will characterize the second best contract and then implement the second best through the double auction.

\subsection{Characterizing the second best contract}

The second best ex ante optimal outcome maximizes the expected sum of utilities of the two parties, subject to incentive compatibility and interim individual-rationality constraints for each agent. As assume above the new bid or the asking price of is $H\left(E\left(\pi_{g}\right) ; E\left(\pi_{f}\right)\right)$. Thus, Governments expected utility (from E5) could be rewritten as follows:

$$
\int_{0}^{1} U_{g}\left(E\left(\pi_{g}\right)\right) d E\left(\pi_{g}\right)=\int_{0}^{1} \int_{0}^{1}\left[H\left(E\left(\pi_{g}\right) ; E\left(\pi_{f}\right)\right)-E\left(\pi_{g}\right) \operatorname{Pr}\left(E\left(\pi_{g}\right) ; E\left(\pi_{f}\right)\right)\right] d E\left(\pi_{f}\right) d E\left(\pi_{g}\right)
$$

The mining company's expected utility equation (from E6) could be rewritten as follows:

$$
\int_{0}^{1} U_{f}\left(E\left(\pi_{f}\right)\right) d E\left(\pi_{f}\right)=\int_{0}^{1} \int_{0}^{1}\left[E\left(\pi_{f}\right) \operatorname{Pr}\left(E\left(\pi_{g}\right) ; E\left(\pi_{f}\right)\right)-H\left(E\left(\pi_{g}\right) ; E\left(\pi_{f}\right)\right)\right] d E\left(\pi_{f}\right) d E\left(\pi_{g}\right)
$$

Therefore the expected sum of utilities of the two parties becomes (E33+E34):

$$
\int_{0}^{1} U_{g}\left(E\left(\pi_{g}\right)\right) d E\left(\pi_{g}\right)+\int_{0}^{1} U_{f}\left(E\left(\pi_{f}\right)\right) d E\left(\pi_{f}\right)=\int_{0}^{1} \int_{0}^{1}\left(E\left(\pi_{f}\right)-E\left(\pi_{g}\right)\right) \operatorname{Pr}\left(E\left(\pi_{g}\right) ; E\left(\pi_{f}\right)\right) d E\left(\pi_{f}\right) d E\left(\pi_{g}\right)
$$

The second-best contract is the solution to the following constraint optimization problem:

$$
V=\max \left[\int_{0}^{1} U_{g}\left(E\left(\pi_{g}\right)\right) d E\left(\pi_{g}\right)+\int_{0}^{1} U_{f}\left(E\left(\pi_{f}\right)\right) d E\left(\pi_{f}\right)\right]
$$

Subject to - proposition 2 -

$$
\int_{0}^{1} \int_{0}^{1}\left(2 E\left(\pi_{f}\right)-2 E\left(\pi_{g}\right)-1\right) \operatorname{Pr}\left(E\left(\pi_{g}\right) ; E\left(\pi_{f}\right)\right) d E\left(\pi_{g}\right) d E\left(\pi_{f}\right)
$$


When the solution holds, all incentive-compatibility and interim individualrationality constraints are satisfied. The constraint must be binding at the optimum. Now one can implement the objective function through the double auction.

\subsubsection{Implementing the second-best through the double auction}

If trade occurs at an average rent level; there exists Bayesian equilibrium of this double auction contract, where the government and the firms best response functions are given by the solutions to:

$$
\max _{\eta_{g}} \int_{\eta_{g}}^{1}\left(H\left(E\left(\pi_{s}\right) ; E\left(\pi_{f}\right)\right)-E\left(\pi_{g}\right)\right) f_{\eta_{f}}\left(\eta_{f}\right) d E\left(\pi_{f}\right) .
$$

and

$$
\max _{\eta_{f}} \int_{0}^{\eta_{f}}\left(E\left(\pi_{f}\right)-H\left(E\left(\pi_{g}\right) ; E\left(\pi_{f}\right)\right)\right) f_{\eta_{g}}\left(\eta_{g}\right) d E\left(\pi_{g}\right)
$$

Assuming that the mining company agrees to pay the price the government claims; it will imply that the government and the mining company have in fact the same valuation for the non-renewable resource. Thus the bid claimed by the mining owner will be paid by the mining operator. Thus the government and the mining company will try to maximize their surplus under the assumption that each party bid is distributed according to the density function. Therefore:

$$
\eta_{g}=\frac{2}{3} E\left(\pi_{g}\right)+\frac{1}{4}
$$

and

$$
\eta_{f}=\frac{2}{3} E\left(\pi_{f}\right)+\frac{1}{12}
$$

This is the agent's strategy, which is also Bayesian Nash equilibrium. The bid versus price paid is indeed the best response functions to one another, and thus form Bayesian Nash equilibrium. In this equilibrium, trade takes place at the rent level:

$$
\eta_{f} \geq \eta_{g}
$$

with

$$
\eta_{g}=H\left(E\left(\pi_{g}\right) ; E\left(\pi_{f}\right)\right)
$$

\section{The second-best contract through the final offer-arbitration}

This analysis follows closely Robert Gibbons' final offer-arbitration steps [4]. The government may ask for an arbitrator to regulate the litigation, as a second strategy. Indeed, the mining codes of some developing countries have legal tendencies within the framework for solving litigations. Let's assume that, the government and the mining company simultaneously make offers. The arbitrator 
knows but the parties do not. The parties believe that the arbitrator offer is randomly distributed according to a cumulative probability distribution, with associated probability density function.

\subsection{The mining owner and the mining operator believe}

The mining firms and the government beliefs are represented in the following probabilities respectively:

$$
\operatorname{Prob}\left\{\eta_{f} \text { chosen }\right\}=\operatorname{Prob}\left\{\eta_{k}<H\left(\eta_{g} ; \eta_{f}\right)\right\}=F\left[H\left(\eta_{g} ; \eta_{f}\right)\right]
$$

and

$$
\text { Prob }\left\{\eta_{g} \text { chosen }\right\}=\operatorname{Prob}\left\{\eta_{k}>H\left(\eta_{g} ; \eta_{f}\right)\right\}=1-F\left[H\left(\eta_{g} ; \eta_{f}\right)\right]
$$

Thus, the expected revenue amount settlement is:

$$
\begin{aligned}
& \eta_{f} \operatorname{Pr} o b\left\{\eta_{k}<H\left(\eta_{g} ; \eta_{f}\right)\right\}+\eta_{g} \operatorname{Pr} o b\left\{\eta_{k}>H\left(\eta_{g} ; \eta_{f}\right)\right\}= \\
& \eta_{f} F\left[H\left(\eta_{g} ; \eta_{f}\right)\right]+\eta_{g}\left(1-F\left[H\left(\eta_{g} ; \eta_{f}\right)\right]\right)
\end{aligned}
$$

Assuming that the mining company wants to minimize the expected rent settlement imposed by the arbitrator; and the government wants to maximize it; the pair of offers represents the Nash equilibrium of negotiation between the both agents; therefore

$\eta_{f}^{*}$ must solve:

$$
\min _{\eta_{f}} \eta_{f} F\left[H\left(\eta_{g}^{*} ; \eta_{f}\right)\right]+\eta_{g}^{*}\left[1-F\left\{H\left(\eta_{g}^{*} ; \eta_{f}\right)\right\}\right]
$$

$\eta_{g}^{*}$ must solve:

$$
\max _{\eta_{g}} \eta_{f}^{*} F\left[H\left(\eta_{g} ; \eta_{f}^{*}\right)\right]+\eta_{g}\left[1-F\left\{H\left(\eta_{g} ; \eta_{f}^{*}\right)\right\}\right]
$$

The price offer pair must meet the first-order conditions for these optimization problems:

$$
\left(\eta_{g}^{*}-\eta_{f}^{*}\right) \frac{1}{2} f\left[H\left(\eta_{g}^{*} ; \eta_{f}^{*}\right)\right]=F\left[H\left(\eta_{g}^{*} ; \eta_{f}^{*}\right)\right]
$$

and

$$
\left(\eta_{g}^{*}-\eta_{f}^{*}\right) \frac{1}{2} f\left[H\left(\eta_{g}^{*} ; \eta_{f}^{*}\right)\right]=\left[1-F\left\{H\left(\eta_{g}^{*} ; \eta_{f}^{*}\right)\right\}\right]
$$

The average of the offers must be equal to the median of the arbitrator's preferred settlement [4]. Substituting the average of the offers into the first order condition for the optimization problems above, we obtain:

$$
\eta_{g}^{*}-\eta_{f}^{*}=\frac{1}{f\left[H\left(\eta_{g}^{*} ; \eta_{f}^{*}\right)\right]}=f^{-1}\left[H\left(\eta_{g}^{*} ; \eta_{f}^{*}\right)\right]
$$


This means, the gap between the offers must equal the reciprocal of the value of the density function of the arbitrator's preferred settlement.

\subsection{The arbitrator's preferred settlement}

Assuming that the arbitrator's preferred settlement is normally distributed around the mean and its variance. The normal distribution is symmetric around its mean; the median of the distribution equals the mean of the distribution. Therefore the Nash equilibrium offers that:

$$
\eta_{g}^{*}=H\left(\eta_{g}^{*} ; \eta_{f}^{*}\right)+\sqrt{\frac{\pi \sigma^{2}}{2}}
$$

and

$$
\eta_{f}^{*}=H\left(\eta_{g}^{*} ; \eta_{f}^{*}\right)-\sqrt{\frac{\pi \sigma^{2}}{2}}
$$

In the equilibrium, the government and the mining company's offers are centered on the expectation of the arbitrator's preferred settlement, and the gap between the offers increases with the parties' uncertainty about the arbitrator's preferred settlement.

\section{Proposition 1}

Fubini's theorem [2] states that if $\boldsymbol{f}$ is integrable on $[a ; b] x[c ; d]$, then:

$$
\int_{a}^{b} \int_{c}^{d} f(x ; y) d x d y=\int_{a}^{b}\left(\int_{c}^{d} f(x ; y) d y\right) d x=\int_{c}^{d}\left(\int_{a}^{b} f(x ; y) d x\right) d y
$$

Thus [1], $\int_{\underline{\theta}}^{\bar{\theta}} u v^{\prime}=[u v]_{\underline{\theta}}^{\bar{\theta}}-\int_{\underline{\theta}}^{\bar{\theta}} u v^{\prime}$, with $v^{\prime}=f(\theta)$ and $u=\int V[q(x)] d x$

So that, $\int_{\underline{\theta}}^{\bar{\theta}}\left(\int_{\underline{\theta}}^{\theta} V[q(x)] d x\right) f(\theta) d \theta=\left[\int_{\underline{\theta}}^{\theta} V[q(x)] d x F(\theta)\right]_{\underline{\theta}}^{\bar{\theta}}-\int_{\underline{\theta}}^{\bar{\theta}} V[q(\theta)] F(\theta) d \theta$

This is equal to, $\quad \int_{\underline{\theta}}^{\bar{\theta}} V[q(\theta)][1-F(\theta)] d \theta$ 


\section{Proposition 2}

The participation constraint of the second-best contract is:

$$
\int_{0}^{1} \int_{0}^{1}\left\{\left(E\left(\pi_{f}\right)-\frac{1-F_{f}\left(E\left(\pi_{f}\right)\right)}{f_{f}\left(E\left(\pi_{f}\right)\right)}\right)-\left(E\left(\pi_{g}\right)+\frac{F_{g}\left(E\left(\pi_{g}\right)\right)}{f_{g}\left(E\left(\pi_{g}\right)\right)}\right)\right\} \operatorname{Pr}\left(E\left(\pi_{g}\right) E\left(\pi_{f}\right)\right) f_{f}\left(E\left(\pi_{f}\right)\right) f_{g}\left(E\left(\pi_{g}\right)\right) d E\left(\pi_{g}\right) d E\left(\pi_{f}\right)
$$

From the uniform distribution's properties, the cumulative distribution and the probability density function of the continuous uniform distribution are:

$$
F_{f}\left(E\left(\pi_{f}\right)\right)=\frac{E\left(\pi_{f}\right)-1}{1-0}=E\left(\pi_{f}\right)-1 ; \text { and } f_{f}\left(E\left(\pi_{f}\right)\right)=\frac{1}{1-0}=1 \forall 0 \leq E\left(\pi_{f}\right) \leq 1
$$

symmetrically,

$$
F_{g}\left(E\left(\pi_{g}\right)\right)=\frac{E\left(\pi_{g}\right)-1}{1-0}=E\left(\pi_{g}\right)-1 ; \text { and } f_{g}\left(E\left(\pi_{g}\right)\right)=\frac{1}{1-0}=1 . \forall 0 \leq E\left(\pi_{g}\right) \leq 1
$$

therefore, the participation constraint becomes,

$$
\int_{0}^{1} \int_{0}^{1}\left(2 E\left(\pi_{f}\right)-2 E\left(\pi_{g}\right)-1\right) \operatorname{Pr}\left(E\left(\pi_{g}\right) ; E\left(\pi_{f}\right)\right) d E\left(\pi_{g}\right) d E\left(\pi_{f}\right)
$$

\section{References}

[1] Dewatripont, M. \&, Bolton, P, Contract Theory, MIT Press, 2004.

[2] Salanié, B. The Economics of Contracts: A Primer, second edition, ISBN10: 0-262-19525-9, ISBN-13: 978-0-262-19525-6, March 2005.

[3] Myerson, R.B. \& Satterhwaite, M.A. Efficient Mechanisms for bilateral trading, Journal of Economic theory, Volume 29, Issue 2, April , 1983.

[4] Gibbons, R.A Primer in Game Theory, ISBN: 0745011594, ISBN13: 9780745011592, 288 pages, paperback, Published by Pearson Higher Education, 1992. 